Journal of

Reinforced Plastics and Composites

\title{
Shape memory characteristics of woven glass fibre fabric- reinforced epoxy composite in flexure
}

\begin{tabular}{|c|c|}
\hline Journal: & Journal of Reinforced Plastics and Composites \\
\hline Manuscript ID: & Draft \\
\hline Manuscript Type: & Original Article \\
\hline Date Submitted by the Author: & $\mathrm{n} / \mathrm{a}$ \\
\hline Complete List of Authors: & $\begin{array}{l}\text { Fejős, Márta; Faculty of Mechanical Engineering, Budapest University of } \\
\text { Technology and Economics, Department of Polymer Engineering } \\
\text { Romhany, Gabor; Faculty of Mechanical Engineering, Budapest University } \\
\text { of Technology and Economics, Department of Polymer Engineering } \\
\text { Karger-Kocsis, Jozsef; Faculty of Mechanical Engineering, Budapest } \\
\text { University of Technology and Economics, Department of Polymer } \\
\text { Engineering }\end{array}$ \\
\hline Keyword: & $\begin{array}{l}\text { shape memory polymer, epoxy, composite, glass fibre fabric, recovery } \\
\text { stress }\end{array}$ \\
\hline Abstract: & $\begin{array}{l}\text { Shape memory characteristics of a woven glass fibre (GF) fabric reinforced } \\
\text { epoxy composite (reinforcement content: } 38 \text { vol.\%) were assessed in three } \\
\text { point bending mode in a dynamic-mechanical analysis device and } \\
\text { compared to those of the parent epoxy resin (EP). From unconstrained } \\
\text { tests the shape fixity and recovery ratios and the recovery rate, whereas } \\
\text { from constrained tests the recovery stress were determined. The shape } \\
\text { fixity and recovery rate decreased due to the GF reinforcement which had, } \\
\text { however, no effect on the shape recovery. Major benefit of the woven GF } \\
\text { fabric was that the recovery stress could be enhanced by two orders of } \\
\text { magnitude in comparison to the neat EP. GF reinforcement was } \\
\text { accompanied with a substantial decrease in the failure-free flexural } \\
\text { deformability of the composite specimen. }\end{array}$ \\
\hline
\end{tabular}

\section{SCHOLARONE ${ }^{m}$ \\ Manuscripts}


SHAPE MEMORY CHARACTERISTICS OF WOVEN GLASS FIBRE FABRICREINFORCED EPOXY COMPOSITE IN FLEXURE

\author{
M. Fejős ${ }^{1}$, G. Romhány ${ }^{1}$ and J. Karger-Kocsis ${ }^{1,2}$ \\ ${ }^{1}$ Department of Polymer Engineering, Faculty of Mechanical Engineering, Budapest \\ University of Technology and Economics, Muegyetem rkp. 3., H-1111 Budapest, \\ Hungary \\ ${ }^{2}$ MTA-BME Research Group for Composite Science and Technology, Muegyetem rkp. \\ 3., H-1111 Budapest, Hungary
}

\title{
Corresponding author:
}

Márta Fejős, Department of Polymer Engineering, Faculty of Mechanical Engineering, Budapest University of Technology and Economics,Müegyetem rkp. 3., Budapest H1111, Hungary.

Email: fejos@pt.bme.hu

Submitted to J. Reinf. Plast. Compos., July, 2012 


\begin{abstract}
Shape memory characteristics of a woven glass fibre (GF) fabric reinforced epoxy composite (reinforcement content: 38 vol.\%) were assessed in three point bending mode in a dynamic-mechanical analysis device and compared to those of the parent epoxy resin (EP). From unconstrained tests the shape fixity and recovery ratios and the recovery rate, whereas from constrained tests the recovery stress were determined. The shape fixity and recovery rate decreased due to the GF reinforcement which had, however, no effect on the shape recovery. Major benefit of the woven GF fabric was that the recovery stress could be enhanced by two orders of magnitude in comparison to the neat EP. GF reinforcement was accompanied with a substantial decrease in the failure-free flexural deformability of the composite specimen.
\end{abstract}

\title{
Keywords
}

shape memory polymer, epoxy, composite, glass fibre fabric, recovery stress 


\section{Introduction}

A shape memory polymer (SMP) is an actively moving polymer, which recovers its original shape from a previously programmed, temporary shape upon an external stimulus. The temporary shape can be achieved by mechanical loading in presence of the external stimulus (usually temperature) and fixed by removing or changing this stimulus.

Primarily, the external stimulus is the temperature increment, which can be triggered by both direct and indirect (i. e., by applying electric current ${ }^{1}$, magnetic field ${ }^{2}$, infrared light ${ }^{3}$ ) heating. The shape memory effect is induced, when the SMP reaches a critical temperature, called transformation temperature $\left(\mathrm{T}_{\text {trans }}\right)$. For thermo-responsive amorphous and semicrystalline SMPs the glass transition temperature $\left(\mathrm{T}_{\mathrm{g}}\right)$ and the melting temperature $\left(T_{m}\right)$ serve as $T_{\text {trans, }}$, respectively. For SMPs with $T_{g}$ as $T_{\text {trans }}$ the shape memory effect can be also initiated by "softening" the SMP with an appropriate solvent ${ }^{4}$, because this is associated with $\mathrm{T}_{\mathrm{g}}$ depression. Researchers prepared also light- ${ }^{5}$ and water-sensitive ${ }^{6}$ SMPs the working principle of which differs from that of thermosensitive SMPs.

SMPs may have many advantages, such as easy processability, low cost, light weight, deformability, biocompatibility, biodegradability, etc. compared to other shape memory materials, like shape memory alloys (SMAs) or shape memory ceramics. However, 
SMPs have some limitations ${ }^{7}$, from which low recovery stress is the most important problem with respect to potential applications. Increasing the low recovery stress (from 4-10 MPa to 200-400 MPa) of SMPs is nowadays a major challenge in this field.

Unconstrained recovery measurements are generally used to characterise the shape memory behaviours (shape fixity, shape recovery), but they do not provide data for the recovery stress. Recovery stress can be quantified in fully or partially constrained recovery tests ${ }^{8}$.

As Rousseau pinpointed ${ }^{7}$, the recovery stress increases with increasing modulus of the SMP. The easiest way to increase the modulus is making SMP composites ${ }^{9}$. Lan et al. ${ }^{10}$ and Ivens et al. ${ }^{11}$ followed this direction by incorporating reinforcing fabrics in styrene based thermosetting SMP resins.

Epoxy based SMPs are covalently crosslinked, amorphous thermosets, whose $T_{g}$ is the $\mathrm{T}_{\text {trans. }}$ Conventional epoxy resins (EP) are used as adhesives, coatings, sealants and as matrices in composites for structural parts. While development of conventional EPs targets $T_{g}$ enhancement ${ }^{12}$, the research with shape memory EPs is rather focusing on $T_{g}$ tailoring for different applications ${ }^{13}$.

Woven glass fibre fabric is one of the most common reinforcements of EPs. Interestingly, the shape memory properties of woven glass fibre fabric/EP composites have been rarely investigated. Therefore this work was aimed at characterising the 
shape memory characteristics of a glass fibre fabric reinforced EP and comparing to those of the neat EP resin. The specimens were subjected to three-point bending tests in a dynamic mechanical analysis (DMA) device to determine the basic shape memory properties. DMA tests were run in both unconstrained and fully constrained conditions whereby avoiding failure onset in the specimens. The constrained DMA tests served to quantify the recovery stress.

\section{Experimental}

Glycerol based aliphatic epoxy resin (ipox MR 3012) and cycloaliphatic amine curing agent (ipox MH 3122) were purchased from Ipox Chemicals (Budapest, Hungary). Woven E-glass fabric with an area density of $250 \mathrm{~g} / \mathrm{m}^{2}$ (E 220, Saint-Gobain Vertex, Litomysl, Czech Republic) was used as reinforcement.

The mixture of EP and curing agent with the stoichiometric ratio was introduced in between two glass plates positioned with silicone rubber strips at a distance of $1 \mathrm{~mm}$ from one another. Polyethylene foil, smeared with mould release agent (Formula Five, Rexco, Conyers, Georgia, USA) was used to facilitate demoulding. Parallel clamps fastened the glass plates and kept in vertical position. The EP resin was poured in the glass plate assembly from its top (Figure 1).

\section{Figure 1}


The woven glass fibre fabric reinforced epoxy composite (EPGF4), containing four layers, was prepared by hand lamination. The glass fibre (GF) content of EPGF4 was 38 vol.\%. Both pure epoxy (EP) and EPGF4 were cured at room temperature for 48 hours and post cured at $80^{\circ} \mathrm{C}$ for 2 hours.

A Q800 dynamic mechanical analyser (DMA, TA Instruments) was used to determine the storage modulus $\left(\mathrm{E}^{\prime}, \mathrm{MPa}\right)$ and the loss angle $(\tan \delta,-)$ as a function of temperature $\left(\mathrm{T},{ }^{\circ} \mathrm{C}\right)$ for the EP and EPGF4. Three-point bending mode was applied with a span length of $20 \mathrm{~mm}$. The width and the thickness of the specimens were approximately 10 $\mathrm{mm}$ and $1 \mathrm{~mm}$, respectively. The scanning range of temperature was $-20 \ldots 150{ }^{\circ} \mathrm{C}$ and a heating rate of $3^{\circ} \mathrm{C} / \mathrm{min}$ and a frequency of $1 \mathrm{~Hz}$ were selected. $\mathrm{T}_{\mathrm{g}}$ was defined as the offset point of $\mathrm{E}^{\prime}(\mathrm{T})$ and the peak position of $\tan \delta(\mathrm{T})$ and denoted by $\mathrm{T}_{\mathrm{g}}{ }^{\mathrm{E}}$ and $\mathrm{T}_{\mathrm{g}}^{\tan \delta}$, respectively.

Force-controlled three-point bending tests were conducted at $90^{\circ} \mathrm{C}$ (deformation temperature, $\mathrm{T}_{\mathrm{d}}$ ) in the above DMA device. The specimen dimensions and the arrangement were the same as written above. Bending speed was $3 \mathrm{~N} / \mathrm{min}$. The stress and strain values were calculated according to EN ISO 178:2001.

In order to determine the shape memory properties two different measurements were performed in the Q800 DMA device. The unconstrained recovery test was used to 
determine the shape fixity ratio, the shape recovery ratio and the speed of recovery. This test contained four steps:

I. Heating up to $T_{d}=90^{\circ} \mathrm{C}$.

II. Bending to the required or maximum deformation $\varepsilon_{m}$ (which was $1 \%$ - see later) with a deformation speed of $0.2 \% / \mathrm{min}$.

III. Fixing the temporary shape: cooling to the storage temperature, $T_{s}=10^{\circ} \mathrm{C}$, while keeping the required deformation (by applying force).

IV/A. Recovering the original shape: heating to $T_{d}=90^{\circ} \mathrm{C}$ while loading the specimen with a minimal force of $0.001 \mathrm{~N}$.

The first three steps were strain-controlled while the fourth one force-controlled. After the third step the specimen relaxed and adapted an $\varepsilon_{u} \leq \varepsilon_{m}$ deformation, which is the fixed temporary shape. The ability of fixing of the required temporary shape $\left(\varepsilon_{m}\right)$ can be calculated by Equation (1), where $R_{f}$ is the shape fixity ratio, $\varepsilon_{u}$ is the fixed temporary shape and $\varepsilon_{m}$ is the required temporary shape. In the fourth step the specimen approached its original shape $\left(\varepsilon_{0}=0\right)$, but it remains some residual deformation, which is the $\varepsilon_{p} \geq \varepsilon_{0}$ recovered shape. The ability of recovering the original shape can be computed by Equation (2), where $R_{r}$ is the shape recovery ratio, $\varepsilon_{m}$ is the required temporary shape and $\varepsilon_{p}$ is the recovered shape, $\varepsilon_{0}$ is the original shape. Speed of the 
recovery is characterised by the recovery rate $(|\mathrm{d} \varepsilon / \mathrm{dt}|, \% / \mathrm{min}$, where $t$ is the time) measured in step IV/A.

$$
\begin{gathered}
R_{f}=\frac{\varepsilon_{u}}{\varepsilon_{m}} 100 \% \\
R_{r}=\frac{\varepsilon_{m}-\varepsilon_{p}}{\varepsilon_{m}-\varepsilon_{0}} 100 \%
\end{gathered}
$$

The other test was conducted under constrained condition to determine the recovery stress $\left(\sigma_{\text {rec }}\right)$. This fully constrained recovery test was carried out in strain-controlled mode. It contains also four steps. The first three steps are identical with those of the unconstrained test (see above). The fourth step was different:

IV/B. Heating up to $T_{d}=90^{\circ} \mathrm{C}$ while keeping the required deformation (by applying force).

The maximum of stress needed during the second and third step can be defined as the programming stress $\left(\sigma_{\text {load }}\right)$. The maximum of stress during the fourth step is the recovery stress $\left(\sigma_{\text {rec }}\right)$. It should be noted that the programming conditions (strain rate, heating rate) were the same for the two samples (i.e. EP and EPGF4). 


\section{Results and Discussion}

The DMA curves (Figure 2) clearly show the effect of the woven GF reinforcement. The GF reinforcement increased prominently the storage modulus, but lowered the difference between the glassy and rubbery moduli, which is proposed to influence the shape memory behaviour ${ }^{14}$. Different glass transition temperatures were read from the

DMA traces: $\mathrm{T}_{\mathrm{g}}{ }^{\mathrm{E}}$ 'values are $50^{\circ} \mathrm{C}$ and $44^{\circ} \mathrm{C}$ whereas the $\mathrm{T}_{\mathrm{g}}^{\tan \delta}$ ones $64^{\circ} \mathrm{C}$ and $59^{\circ} \mathrm{C}$ for the EP and EPGF4, respectively. The observed shift in the $\mathrm{T}_{\mathrm{g}}$ toward lower temperatures in case of the EPGF4 can be traced to the formation of an interphase with higher chain flexibility than the bulk EP. This is obviously an effect of the GF sizing.

\section{Figure 2}

For the deformation temperature $\left(\mathrm{T}_{\mathrm{d}}\right)$ that temperature was selected, where both the samples were in the rubbery state. This was around $90^{\circ} \mathrm{C}$, i.e. approximately $30^{\circ} \mathrm{C}$ higher than $T_{g}$. In order to determine the deformability of the samples at $T_{d}$ flexural tests were conducted.

As expected, the EPGF4 had 2 orders of magnitude larger flexural modulus (3649 MPa compared to $32 \mathrm{MPa}$ for $\mathrm{EP}$ ), and one order of magnitude larger flexural stress at failure (46 MPa compared to $2 \mathrm{MPa}$ for $\mathrm{EP}$ ) than the neat $\mathrm{EP}$ at $90^{\circ} \mathrm{C}$. As a negative effect, the reduction in the flexural strain at failure should be noted. It decreased from $6.6 \%$ (EP) to $1.3 \%$ (EPGF4). Figure 3 displays the flexural sress-strain curves of the samples. 
Failure of the EPGF4 specimen occurred at its compression side, where the glass fabric delaminated and bent in the opposite direction of the bending.

\section{Figure 3}

For shape memory tests an appropriate maximal strain $\left(\varepsilon_{m}\right)$ level should be chosen. Its value should be as high as possible but without causing any failure in the specimen. Based on Figure 3 the $\varepsilon_{m}=1 \%$ was selected.

With help of the unconstrained recovery test the basic shape memory characteristics of the samples can be quantified. Figure 4 shows the temperature program, stress and strain values during the test. After deforming the pure EP to $\varepsilon_{m}$ and immediate cooling to $T_{\mathrm{s}}$ the stress decreases almost to zero which suggests good shape fixity. The strain shows a small increase during step III, due to thermal contraction. This thermal contraction leads to a shape fixity of $103 \%$ for the EP though the theoretical maximum value of shape fixity is $100 \%$.

\section{Figure 4}

In case of EPGF4 the stress decreases during cooling, but does not reach zero. Therefore, after step III the strain displays a prominent decrease, which implies that its shape fixity is worse than that of the EP. Table 1 lists the determined shape memory properties of the samples. 


\section{Table 1}

Note that both samples show very good shape recovery ratio ( $99 \%$ each). On the other hand, EPGF4 exhibited a lower maximal recovery rate compared to the neat EP, as Figure 5 shows.

\section{Figure 5}

From the three dimensional (3D) temperature-stress-strain plots (Figure 6) the decrease in shape fixity due to the woven GF reinforcement it turns out very clearly. The 3D representation also evidences the stress increment needed to deform the composite specimen. The latter implies an increase in the recovery stress.

\section{Figure 6}

Fully constrained recovery tests were aimed at determining the recovery forces (Figure 7Error! Reference source not found.). Recall that the first three steps of this test agree with those of the unconstrained recovery test. Loading (or programming) stress $\left(\sigma_{\text {load }}\right)$ and recovery stress $\left(\sigma_{\text {rec }}\right)$ are the maximum stress values observed during bending deformation (step II) and during recovery (step IV/B), respectively. Woven GF reinforcement increased $\sigma_{\text {rec }}$ of the EP by two orders of magnitude (Table 1). This is very beneficial for such application of shape memory composites where high recovery forces are needed (e.g. actuators). Note that $\sigma_{\text {rec }}$ and $\sigma_{\text {load }}$ for both EP and EPGF4 are 
almost equal. This fact suggests that no crack or other type of failure occurred during the shaping/programming step.

\section{Figure 7}

\section{Conclusion}

This work was devoted to compare the shape memory characteristics of an epoxy resins (EP) and its composite containing 4 layers woven glass fibre (GF) fabric reinforcement (EPGF4; GF content: 38 vol.\%). The shape memory properties were determined in flexure using a dynamic-mechanical analysis (DMA) device working under both unconstrained and constrained conditions. It was found that the shape fixity (from 103 to $81 \%$ ) and recovery rate (from 0.51 to $0.37 \% / \mathrm{min}$ ) decreased due to the GF reinforcement. By contrast, the reinforcement did not affect the shape recovery and strongly enhanced the recovery stress (from 0.4 to $42 \mathrm{MPa}$ ). This was, however, associated with a large decrease in the failure-free flexural deformability of the composite specimen (from 6.6 to $1.2 \%$ ).

\section{Funding}

This work was supported by the Hungarian Research Fund [OTKA NK 83421]; by the scientific programs: "Development of quality-oriented and harmonized $\mathrm{R}+\mathrm{D}+\mathrm{I}$ strategy 
and functional model at BME" [TÁMOP 4.2.1/B-09/1/KMR-2010-0002]; and „Talent care and cultivation in the scientific workshops of BME" [TÁMOP 4.2.2/B-10/1-20100009].

\section{References}

1. Lan X, Leng, JS, Liu YJ and Du SY. Investigate of electrical conductivity of shapememory polymer filled with carbon black. Adv Mater Res 2008; 47-50: 714-717.

2. Kumar UN, Kratz K, Behl M and Lendlein A. Shape-memory properties of magnetically active triple-shape nanocomposites based on a grafted polymer network with two crystallizable switching segments. Express Polymer Letters 2012; 6: 26-40.

3. Leng $\mathrm{J}, \mathrm{Wu} \mathrm{X}$ and Liu Y. Infrared light-active shape memory polymer filled with nanocarbon particles. J. Appl Polym Sci 2009; 114: 2455-2460.

4. Huang WM, Yang B, An L, Li C and Chan YS. Water-driven programmable polyurethane shape memory polymer: Demonstration and mechanism. Appl Phys Lett 2005; 86: 114105/1-114105/3.

5. Lendlein A, Jiang HY, Junger $\mathrm{O}$ and Langer R. Light-induced shape-memory polymers. Nature $2005 ; 434: 879-882$. 
6. Fan K, Huang WM, Wang CC, Ding Z, Zhao Y, Purnawali H, Liew KC and Zheng LX. Water-responsive shape memory hybrid: Design concept and demonstration. Express Polymer Letters 2011; 5: 409-416.

7. Rousseau IA. Challenges of shape memory polymers: A review of the progress toward overcoming SMP's limitations. Polym Eng Sci 2008; 48: 2075-2089.

8. Lakhera N, Yakacki CM, Nguyen TD and Frick CP. Partially constrained recovery of (meth)acrylate shape-memory polymer networks. J Appl Polym Sci 2012; in press, DOI: $10.1002 /$ app.36612.

9. Ware T, Ellson G, Kwasnik A, Drewicz S, Gall K and Voit W. Tough shape-memory polymer-fiber composites. J Reinf Plast Compos 2011; 30: 371-380.

10. Lan X, Liu Y, Lv H, Wang X, Leng J and Du S. Fiber reinforced shape-memory polymer composite and its application in a deployable hinge. Smart Mater Struct 2009; 18: $024002 / 1-024002 / 6$.

11. Ivens J, Urbanus $M$ and De Smet C. Shape recovery in a thermoset shape memory polymer and its fabric-reinforced composites. Express Polymer Letters 2011; 5: 254261. 
12. Yi JW, Um MK, Byun JH, Lee SB and Lee SK. Development of high Tg epoxy resins and mechanical properties of its fiber-reinforced composites. J Appl Polym Sci 2012; in press, DOI: 10.1002/app.38040.

13. Xie T and Rousseau IA. Facile tailoring of thermal transition temperature of epoxy shape memory polymers. Polymer 2009, 50: 1852-1856.

14. Ratna D and Karger-Kocsis J. Recent advances in shape memory polymers and composites: A review. J Mater Sci 2008; 43: 254-269. 


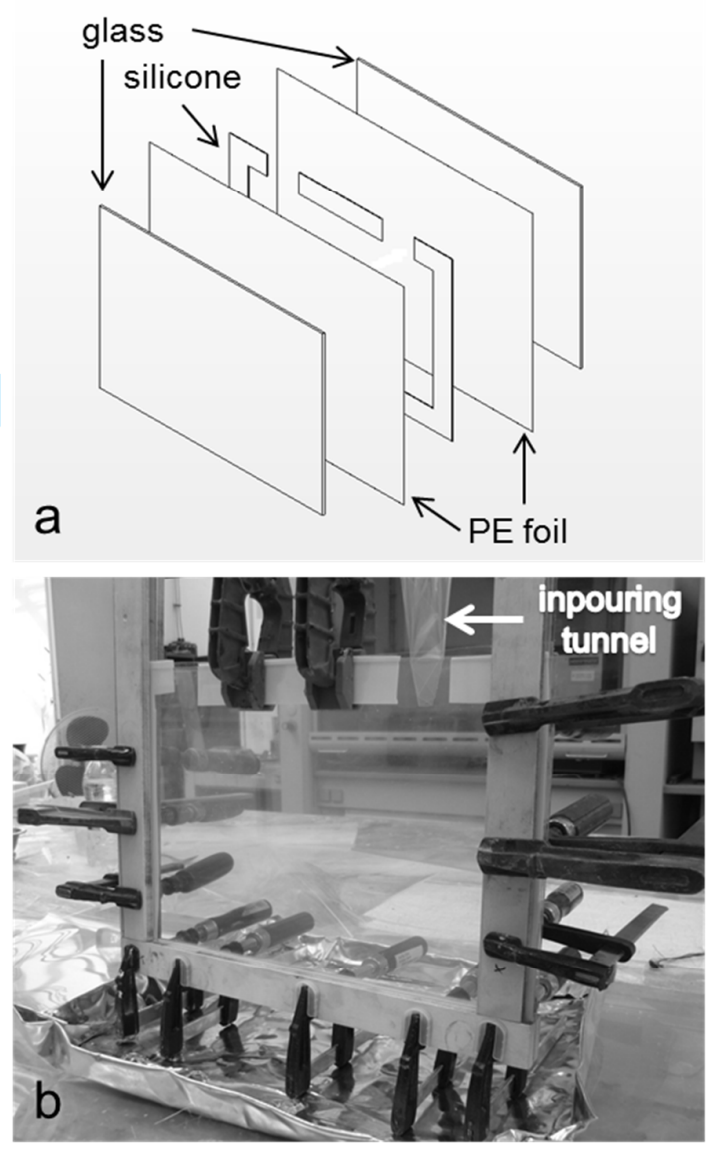

Figure 1. Glass mould for sample preparation of the neat EP:

(a) exploded assembly (b) photograph. 


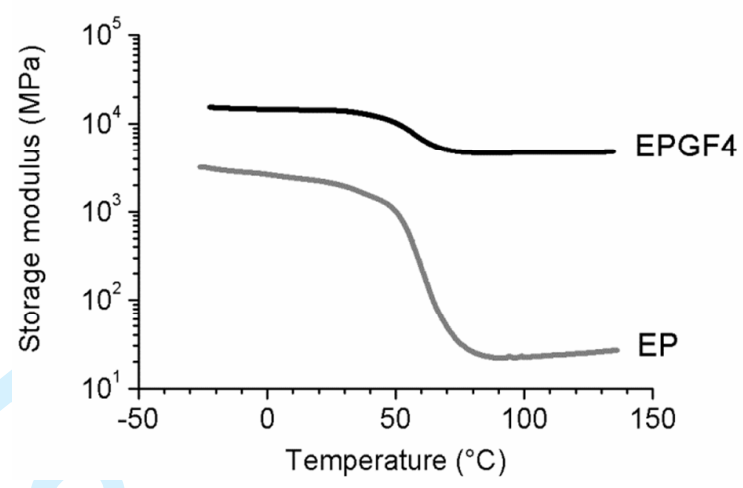

Figure 2. DMA curves of EP and EPGF4.

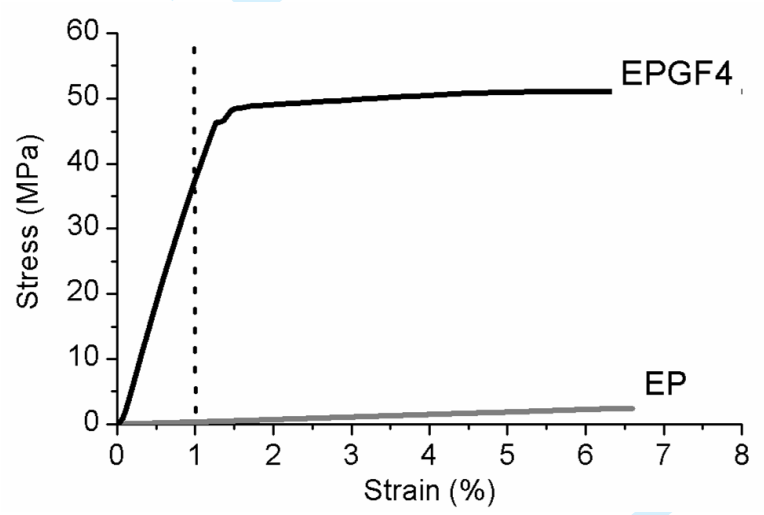

Figure 3. Stress-strain curves of EP and EPGF4 at $\mathrm{T}_{\mathrm{g}}+30^{\circ} \mathrm{C}$. Dashed line indicates the maximal strain $\left(\varepsilon_{m}\right)$ applied during the shape memory tests. 

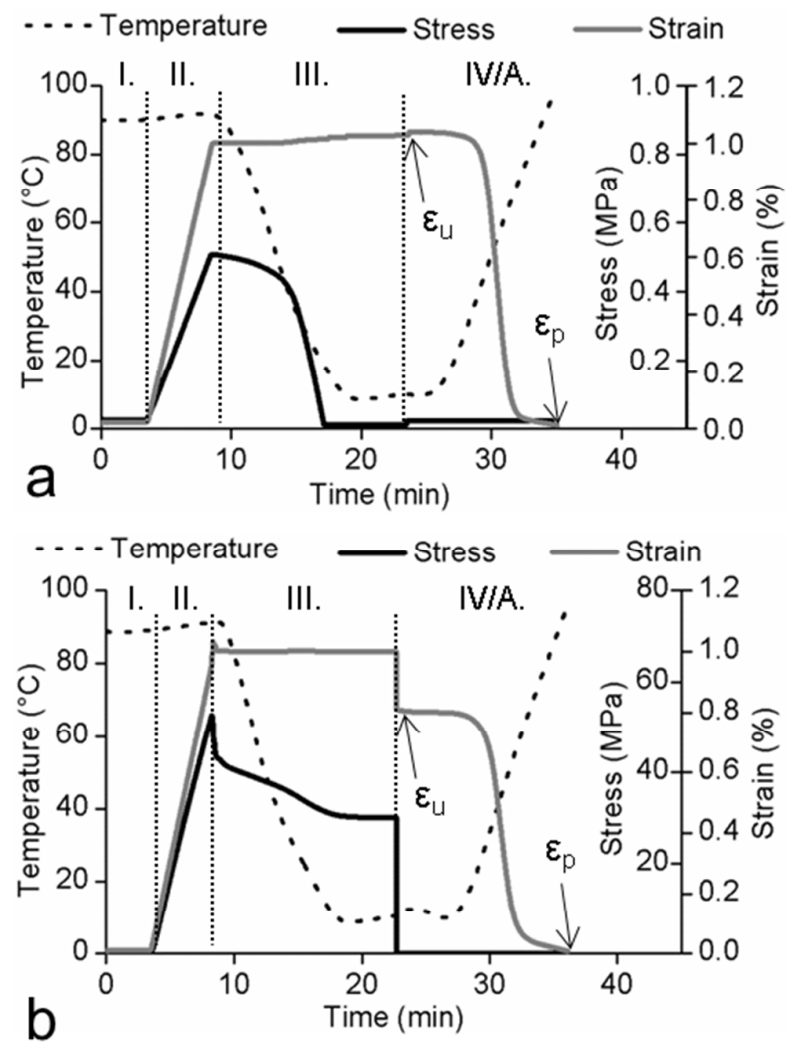

Figure 4. Unconstrained recovery tests on (a) EP and (b) EPGF4. 


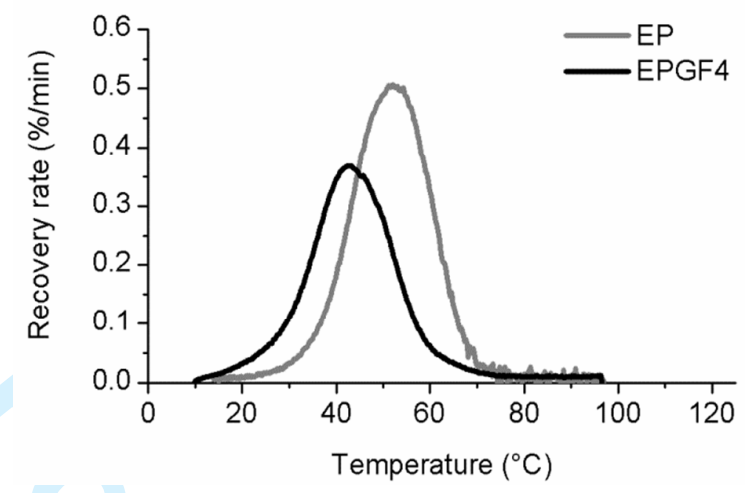

Figure 5. Recovery rate of EP and EPGF4 as a function of temperature.

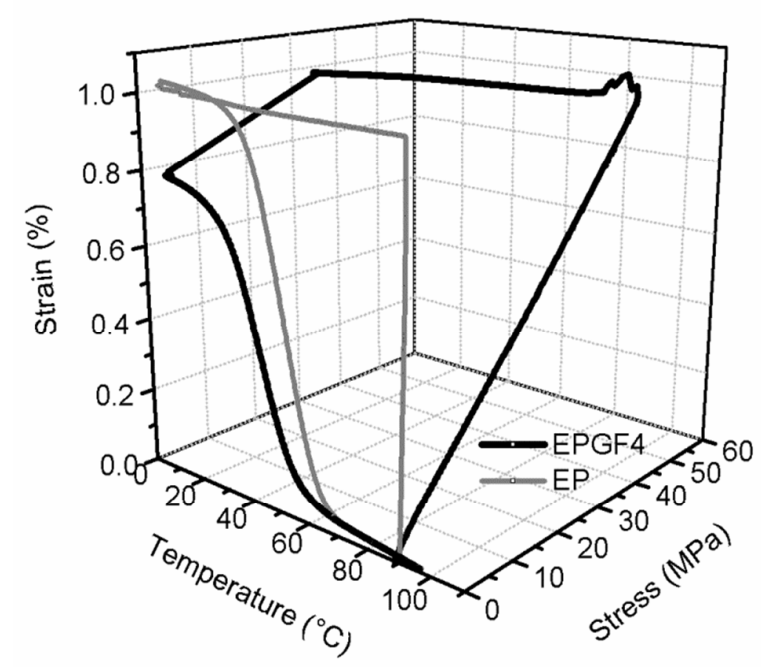

Figure 6. 3D temperature - stress - strain curves of EP and EPGF4. 

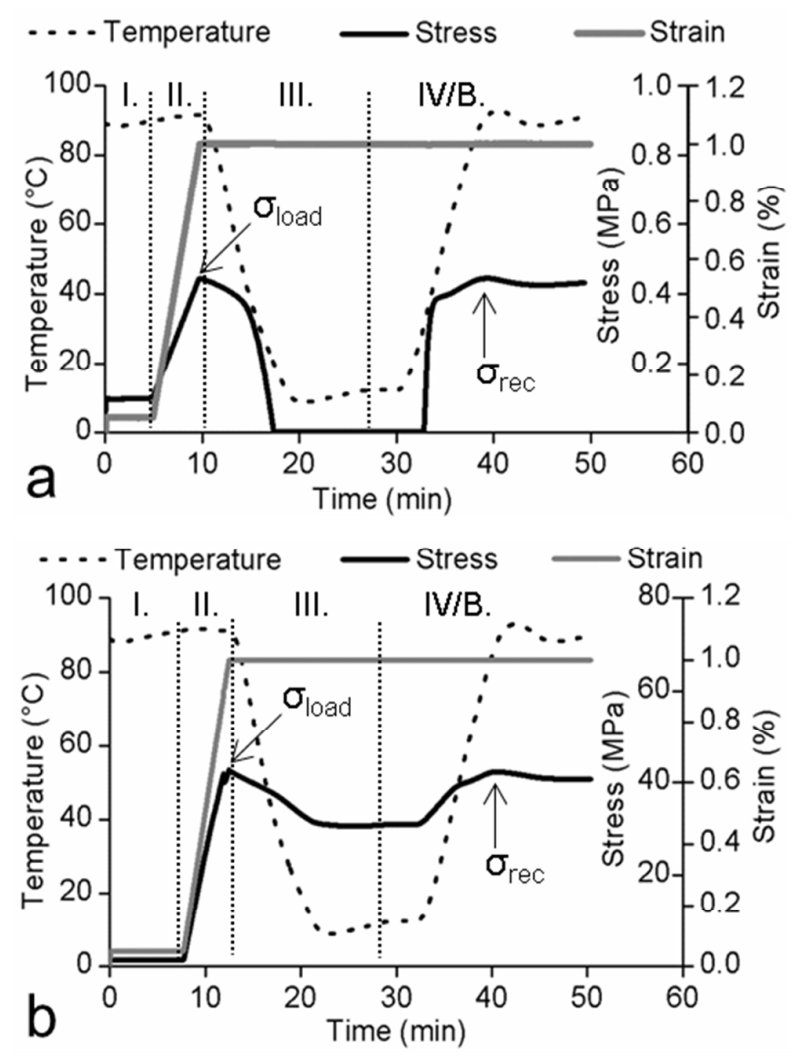

Figure 7. Constrained recovery tests on (a) EP and (b) EPGF4. 
Table 1. Shape memory properties of EP and EPGF4.

\begin{tabular}{lll}
\hline Properties & EP & EPGF4 \\
\hline$\varepsilon_{0}(\%)$ & 0 & 0 \\
$\varepsilon_{\mathrm{m}}(\%)$ & 1 & 1 \\
$\varepsilon_{\mathrm{u}}(\%)$ & 1.03 & 0.81 \\
$\varepsilon_{\mathrm{p}}(\%)$ & 0.01 & 0.01 \\
$\mathrm{R}_{\mathrm{f}}(\%)$ & 103 & 81 \\
$\mathrm{R}_{\mathrm{r}}(\%)$ & 99 & 99 \\
$|\mathrm{~d} \varepsilon / \mathrm{dt}|_{\max }(\% / \min )$ & 0.50 & 0.38 \\
$\mathrm{~T}_{\mathrm{r}}\left({ }^{\circ} \mathrm{C}\right)$ & 51 & 44 \\
$\sigma_{\text {load }}(\mathrm{MPa})$ & 0.44 & 42.74 \\
$\sigma_{\text {rec }}(\mathrm{MPa})$ & 0.44 & 42.33 \\
\hline
\end{tabular}

